\title{
UJI FITOKIMIA DAN UJI TOKSISITAS EKSTRAK ETANOL TANAMAN KESEMBUKAN (Paederia foetida Linn.) DENGAN METODE BRINE SHRIMP LETHALITY TEST
}

\author{
Datin An Nisa Sukmawati ${ }^{1}$, Elok Kamilah Hayati ${ }^{1}$, Roihatul Muti'ah ${ }^{2}$ \\ ${ }^{1}$ Jurusan Kimia, Fakultas Sains dan Teknologi, UIN Maulana Malik Ibrahim Malang \\ ${ }^{2}$ Jurusan Farmasi, Fakultas Sains dan Teknologi, UIN Maulana Malik Ibrahim Malang
}

\begin{abstract}
Kesembukan plant (Paederia foetida L.) is one of the plants from the Rubiaceae tribe which has been used by the people to cure thrush, fever, blown, high blood pressure, arthritis and herpes. The purposes of this research are to determine the level of toxicity of each Kesembukan plant extracts against the Artemia salina L. and to find the content of the compounds contained in each Kesembukan plant extract.

The research was conducted by extracting the sample using ethanol, chloroform and n-hexane. The concentrated extract was used to test the toxicity of Artemia salina L. using Brine Shrimp Lethality Test method (Meyer, et al., 1982) and phytochemicals with reagents. Compounds from phytochemical test results were identified using thin layer chromatography with the eluents to find out the best eluent. The mortality data of Artemia salina $\mathrm{L}$. were analyzed by probit analysis to find $\mathrm{LC}_{50}$ values of each extract.

The results of this research show that each extract of Kesembukan plant (Paederia foetida L.) has the level of toxicity against Artemia salina L. with $\mathrm{LC}_{50}$ values indicated less than $1000 \mathrm{ppm}$. $\mathrm{LC}_{50}$ values of each extract ethanol, chloroform and n-hexane was 226,787; 482,014, and 146,181 ppm. Content of compounds from phytochemical test result using the reagent for each Kesembukan plant extract are the class of steroid compound. The best eluent for the separation of steroid compound in ethanol extract is n-hexane: ethyl acetate (8:2) with the values of $\mathrm{Rf}=0.22$ and 0.48 and for chloroform extract is $n$-hexane: ethyl acetate $(7: 3)$ with the values of $\mathrm{Rf}=$ $0.32 ; 0.45 ; 0.59 ; 0.63 ; 0.82 ; 0.85 ; 0.87$ and 0.94 and for $n$-hexane extract is $n$-hexane: ethyl acetate $(8: 2)$ with the values of $\mathrm{Rf}=0.12 ; 0.38$ and 0.41 .
\end{abstract}

Keywords : Kesembukan plant (Paederia foetida Linn, Artemia salina Leach, toxicity test, phytochemical test

\begin{abstract}
ABSTRAK
Tanaman Kesembukan (Paederia foetida L.) merupakan salah satu tanaman dari suku Rubiaceae (kopikopian) yang telah digunakan oleh masyarakat sebagai obat sariawan, obat demam, sesak nafas, obat tekanan darah tinggi, rematik dan herpes. Tujuan dari penelitian ini adalah untuk mengetahui tingkat toksisitas masingmasing ekstrak tanaman Kesembukan terhadap larva udang Artemia salina L. dan untuk mengetahui kandungan senyawa yang terkandung dalam masing-masing ekstrak tanaman kesembukan.

Penelitian ini dilakukan dengan mengekstraksi sampel menggunakan pelarut etanol, kloroform dan nheksana. Ekstrak pekat yang diperoleh digunakan untuk uji toksisitas terhadap larva udang Artemia salina L. dengan metode Brine Shrimp Lethality Test (Meyer, et al., 1982) dan untuk uji fitokimia dengan reagen. Senyawa dari hasil uji fitokimia diidentifikasi menggunakan kromatografi lapis tipis dengan beberapa eluen untuk mengetahui eluen yang terbaik. Data kematian larva udang Artemia salina L. dianalisis dengan analisis probit untuk mengetahui nilai $\mathrm{LC}_{50}$ pada masing-masing ekstrak.

Hasil dari penelitian ini menunjukkan bahwa masing-masing ekstrak tanaman Kesembukan (Paederia foetida L.) memiliki tingkat toksisitas terhadap larva udang Artemia salina L.yang ditunjukkan dengan nilai $\mathrm{LC}_{50}$ kurang dari 1000 ppm. Nilai LC $_{50}$ masing-masing ekstrak etanol, kloroform dan n-heksana adalah 226,787; 482,014; dan 146,181 ppm. Kandungan senyawa hasil uji fitokimia menggunakan reagen untuk masing-masing ekstrak tanaman Kesembukan adalah golongan senyawa steroid. Eluen terbaik untuk pemisahan senyawa pada ekstrak etanol adalah $\mathrm{n}$-heksana : etil asetat (8:2) dengan nilai $\mathrm{Rf}=0,22$ dan 0,48 . Pada ekstrak kloroform adalah $\mathrm{n}$-heksana : etil asetat $(7: 3)$ dengan nilai $\mathrm{Rf}=0,32 ; 0,45 ; 0,59 ; 0,63 ; 0,82 ; 0,85 ; 0,87$ dan 0,94 . Pada ekstrak nheksana adalah n-heksana : etil asetat (8:2) dengan nilai $\mathrm{Rf}=0,12 ; 0,38$ dan 0,41 .
\end{abstract}

Kata Kunci: Tanaman Kesembukan (Paederia foetida Linn), Artemia salina Leach, uji toksisitas, uji fitokimia 


\section{PENDAHULUAN}

Tanaman kesembukan (Paederia foetida L.) merupakansalah satu tanaman dari suku Rubiaceae (kopi-kopian) yang dapat hidup di daerah tropis dan merupakan tanaman perdu. Keberadaan tanaman kesembukan ini sudah melimpah dan banyak dimanfaatkan oleh masyarakat sebagai makanan, minuman, dan bahan obat (Rukmana, 2002). Selain itu, masyarakat percaya bahwa tanaman kesembukan dapat menyembuhkan beberapa penyakit seperti diare, sariawan, demam, sesak nafas, tekanan darah tinggi, rematik, herpes dan disentri (Wijayakusuma, 2002).

BSLT (Brine Shrimp Lethality Test) digunakan untuk menentukan toksisitas suatu ekstrak atau senyawa.Uji toksisitas terhadap larva udang Artemia salina L. atau BSLT dapat digunakan sebagai uji pendahuluan pada penelitian yang mengarah pada uji sitotoksik.Parameter yang ditunjukkan untuk menunjukkan adanya aktivitas biologi pada suatu senyawa pada Artemia salina L. adalah kematiannya. Penggolongan toksisitas atas dasar jumlah besarnya zat kimia yang diperlukan untuk menimbulkan bahaya untuk harga LC50 dibedakan menjadi (Meyer, etal., 1982) :

a. Toksik (LC50 < $1000 \mathrm{ppm})$.

b. Tidak toksik (LC50> 1000 ppm).

Penelitian yang dilakukan oleh Morshed, et al., (2012) menyebutkan bahwa ekstrak metanol tanaman kesembukan memiliki bioaktivitas yang tinggi dengan nilai LC50 sebesar 1,5625 ppm. Tetapi pada penelitian tersebut belum dilakukan identifikasi golongan senyawa apa yang berperan dalam tingginya bioaktivitas tersebut. Berdasarkan penelitian tersebut maka dilakukan penelitian tentang uji toksisitas tanaman kesembukan dengan menggunakan pelarut etanol.

\section{METODE PENELITIAN}

Pelaksanaan Penelitian

Penelitian dilaksanakan di

Laboratorium Kimia Organik dan Laboratorium Riset Kimia Analitik Universitas Islam Negeri Maulana Malik
Ibrahim Malang pada bulan Januari 2013 sampai bulan Mei 2013.

\section{Alat dan Bahan Penelitian}

Alat-alat yang digunakan adalah seperangkat alat gelas, rotary evaporator, neraca analitik, kertas saring, gelas vial, penyaring Buchner vaccum, shaker, mikropipet, lampu, aerator dan tabung reaksi.

Bahan yang digunakan meliputi tanaman kesembukan, etanol, aquades, larva udang Artemia salina L., DMSO, ragi roti, air laut, reagen Meyer, reagen Lieberman-Burcard.

\section{CARA KERJA}

\section{Preparasi Sampel}

Sampel tanaman kesembukan diambil bagian daun dan batangnya kemudian dicuci dan dikeringanginkan. Selanjutnya, dipotong kecil-kecil, dan dikeringkan dengan oven pada suhu 30$37^{\circ} \mathrm{C}$ selama 2 jam dan dihaluskan sampai berbentuk serbuk. Kemudian diayak dengan ukuran 60 mesh. Hasil yang diperoleh digunakan sebagai sampel penelitian.

\section{Ekstraksi Senyawa Aktif dengan Maserasi}

Serbuk tanaman kesembukan (Paederia foetida L.) ditimbang sebanyak $60 \mathrm{~g}$ dan diekstraksi dengan perendaman menggunakan $300 \mathrm{~mL}$ pelarut etanol selama 24 jam. Pengadukan dibantu dengan shaker, kemudian disaring dan ampasnya dimaserasi kembali dengan pelarut yang sama sampai diperoleh ampas yang pucat. Masing-masing filtrate diuapkan pelarutnya menggunakan rotary evaporator untuk mendapatkan ekstrak pekat etanol.

\section{Uji Toksisitas dengan Larva Udang} Artemia salina $\mathbf{L}$.

Telur larva udang Artemia salina L. ditimbang 2,5 $\mathrm{mg}$ dan dimasukkan ke dalam bejana penetasan yang berisi air laut $250 \mathrm{~mL}$. Diaerasi menggunakan aerator dan diberi lampu. Penetasan dilakukan selama 48 jam.

Ekstrak etanol tanaman kesembukan ditimbang sebanyak $10 \mathrm{mg}$, dilarutkan dengan menggunakan $100 \mu \mathrm{L}$ dimetil sulfoksida (DMSO) dan ditambahkan 
sedikit air laut. Dipindahkan pada labu takar $10 \mathrm{~mL}$ dan ditanda bataskan sampai volume $10 \mathrm{~mL}$ untuk membuat larutan stok 1000 ppm (Febriany, 2004). Kemudian, dipipet sebanyak $8 \mathrm{~mL}$; $4 \mathrm{~mL} ; 2 \mathrm{~mL} ; 1 \mathrm{~mL}$; $0,5 \mathrm{~mL} ; 0,25 \mathrm{~mL} ; 0,125 \mathrm{~mL} ; 0,0625 \mathrm{~mL}$; $0,03125 \mathrm{~mL} ; 0,015625 \mathrm{~mL}$; dan $0,0078 \mathrm{~mL}$, dimasukkan ke dalam labu takar $10 \mathrm{~mL}$.

Selanjutnya, ditambahkan setetes larutan ragi roti, ditambahkan dengan air laut sampai tanda batas $10 \mathrm{~mL}$ dan dikocok sampai homogen, sehingga konsentrasinya $800 ; 400 ; 200 ; 100 ; 50 ; 25 ; 12,5 ; 6,25$; 3,$125 ; 1,5625$; dan 0,78 ppm (Morshed, et al., 2012).Kontrol dibuat dengan cara yang sama tanpa adanya penambahan ekstrak.

Selanjutnya, larutan dipindahkan ke dalam gelas vial dan dimasukkan 10 ekor larva udang Artemia salina L.. Pengamatan dilakukan selama 24 jam terhadap kematian larva udang. Analisis data yang dilakukan untuk mencari nilai LC50 adalah dengan analisis probit menggunakan Minitab 16 (Halimah, 2010).

\section{Uji Fitokimia dengan Reagen Uji Flavonoid}

Ekstrak etanol tanaman kesembukan masing-masing diambil $1 \mathrm{mg}$. Kemudian dilarutkan dalam 1-2 mL metanol panas 50 $\%$. Setelah itu ditambah logam Mg dan 4-5 tetes $\mathrm{HCl}$ pekat. Larutan berwarna merah atau jingga yang terbentuk menunjukkan adanya flavonoid (Halimah, 2010).

\section{Uji Alkaloid}

Ekstrak etanol tanaman kesembukan diambil $1 \mathrm{mg}$, ditambah 0,5 $\mathrm{mL} \mathrm{HCl} 2 \%$ dan larutan dibagi dalam dua tabung. Tabung I ditambahkan 2-3 tetes reagen Dragendroff, tabung II ditambahkan 2-3 tetes reagen Mayer. Jika tabung I terbentuk endapan jingga dan pada tabung II terbentuk endapan kekuning-kuningan, menunjukkan adanya alkaloid (Halimah, 2010).

\section{Uji Tanin}

\section{Uji dengan $\mathrm{FeCl}_{3}$}

Ekstrak etanol tanaman kesembukan diambil $1 \mathrm{mg}$, ditambahkan dengan 2-3 191 tetes larutan $\mathrm{FeCl}_{3} 1 \%$. Jika larutan menghasilkan warna hijau kehitaman atau biru tua, maka ekstrak tersebut mengandung tanin (Halimah, 2010).

\section{Uji dengan Larutan Gelatin}

Ekstrak etanol tanaman kesembukan diambil $1 \mathrm{mg}$, ditambah dengan larutan gelatin. Jika terbentuk endapan putih, maka ekstrak tersebut mengandung tanin (Halimah, 2010).

\section{Uji Tanin Katekol dan Tanin Galat}

Ekstrak etanol tanaman kesembukan diambil $1 \mathrm{mg}$, ditambahkan dengan larutan formaldehid $3 \%$ : asam klorida pekat (2:1) dan dipanaskan dalam air panas dengan suhu $90{ }^{\circ} \mathrm{C}$. Jika terbentuk endapan merah, maka ekstrak tersebut menunjukkan adanya tanin katekol. Filtrat dijenuhkan dengan Na-asetat dan ditambahkan larutan $\mathrm{FeCl}_{3} 1$ $\%$. Jika terbentuk warna biru tinta atau hitam, maka ekstrak tersebut menunjukkan adanya tanin galat (Halimah, 2010).

\section{Uji Saponin}

Ekstrak etanol tanaman kesembukan diambil $1 \mathrm{mg}$, ditambah air (1:1) dan sambil dikocok selama 1 menit, apabila menimbulkan busa ditambahkan $\mathrm{HCl} 1 \mathrm{~N}$, busa yang terbentuk dapat bertahan selama 10 menit dengan ketinggian 1-3 cm, maka ekstrak positif mengandung saponin (Halimah, 2010).

\section{Uji Triterpenoid dan Steroid}

Ekstrak etanol tanaman kesembukan diambil $1 \mathrm{mg}$, dilarutkan dalam $0,5 \mathrm{~mL}$ kloroform dan ditambah dengan $0,5 \mathrm{~mL}$ asam asetat anhidrat. Campuran ini selanjutnya ditambah dengan 1-2 $\mathrm{mL}$ $\mathrm{H}_{2} \mathrm{SO}_{4}$ pekat melalui dinding tabung tersebut. Jika hasil yang diperoleh berupa cincin kecoklatan atau violet pada perbatasan dua pelarut maka ekstrak tersebut menunjukkan adanya triterpenoid, sedangkan jika hasil yang diperoleh terbentuk warna hijau kebiruan maka ekstrak tersebut menunjukkan adanya steroid (Halimah, 2010).

\section{HASIL DAN PEMBAHASAN \\ Uji Toksisitas dengan Larva Udang Artemia salina $\mathbf{L}$.}


Parameter yang digunakan pada uji toksisitas adalah bioaktivitas suatu senyawa terhadap larva udang Artemia salina L. dengan menghitung kematiannya yang nilai LC50< 1000 ppm (Meyer, et al., 1982). Pada penelitian ini hasil uji toksisitas ekstrak etanol dianalisis probit dengan program Minitab 16. Kurva mortalitas yang didapat adalah :

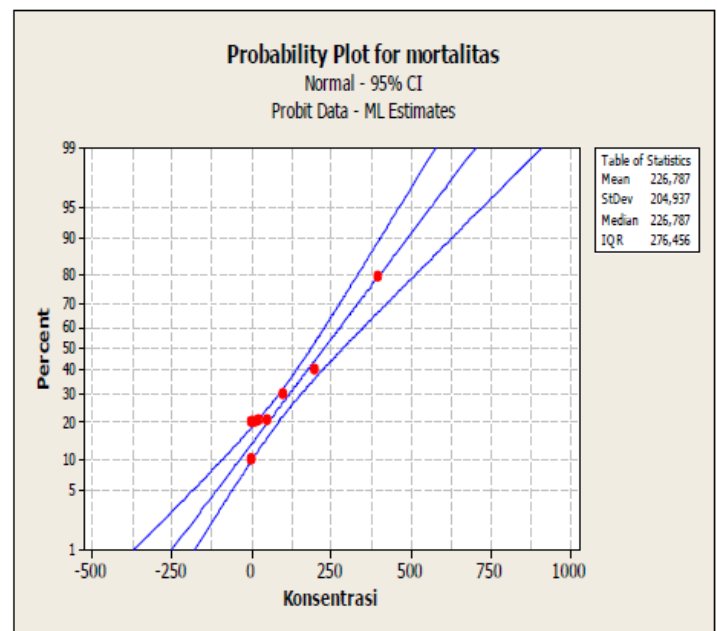

Gambar 1. Kurva mortalitas Larva Udang Artemia salina L. terhadap ekstrak etanol tanaman kesembukan dengan LC50= 226,787 ppm

Berdasarkan kurva mortalitas diatas ekstrak etanol tanaman kesembukan memiliki nilai LC50 < 1000 ppm, maka ekstrak tersebut memiliki bioaktivitas terhadap larva udang Artemia salina L. pada nilai $\mathrm{LC} 50=226,787 \mathrm{ppm}$.

\section{Uji Fitokimia dengan Reagen}

Uji fitokimia dalam penelitian ini dilakukan pada golongan senyawa flavonoid, alkaloid, tanin, steroid, triterpenoid, dan saponin dengan menggunakan reagen masing-masing. Hasil uji fitokimia dengan reagen ditunjukkan pada Tabel 1.

Tabel 1.Hasil identifikasi uji fitokimia ekstrak etanol tanaman kesembukan dengan Reagen.

\begin{tabular}{|c|c|}
\hline $\begin{array}{c}\text { Golongan } \\
\text { genyawa }\end{array}$ & Elstak etanol \\
\hline Flawonoid & - \\
\hline Tamin & - \\
\hline Alkaloid & - \\
\hline Saponin & - \\
\hline Triterpowid & - \\
\hline Steroid & + \\
\hline
\end{tabular}

Keterangan:

Tanda - : tidak terkandung senyawa

Tanda + : terkandung senyawa

\section{KESIMPULAN DAN SARAN Kesimpulan}

Ekstrak etanol tanaman kesembukan (Paederia foetida L.) memiliki toksisitas terhadap larva udang Artemia salina L., ditunjukkan dengan nilai LC50< 1000 ppm. Nilai LC50 dari ekstrak etanol226,787 ppm.

Golongan senyawa dalam ekstrak etanol tanaman kesembukan (Paederia foetida L.) berdasarkan uji fitokimia dengan reagen adalah golongan senyawa steroid

Saran

Perlu dilakukan identifikasi dan pemisahan senyawa dengan menggunakan kromatografi lapis tipis (KLT).

\section{DAFTAR PUSTAKA}

Febriany, S. 2004. Pengaruh Beberapa Ekstrak Tunggal Banle dan Gabungannya yang Berpotensi Meningkatkan Aktivitas Enzim Lipase Secara In Vitro. Skripsi. Bogor : Jurusan Kimia Fakultas Matematika dan Ilmu Pengetahuan Alam Institut Pertanian Bogor.

Halimah, N. 2010. Uji Fitokimia dan Uji Toksisitas Ekstrak Tanaman AntingAnting (Acalypha indica Linn.) terhadap Larva Udang Artemia salina Leach. Skripsi Diterbitkan. Malang: Fakultas Sains dan Teknologi Universitas Islam Negeri Maulana Malik Ibrahim Malang.

Meyer, B.N. Ferrigni, P. J.E, Jacobsen. L.B, Nichols and McLaughlin.1982. 
Brine Shrimp: A Convenient

General Bioassay for Active Plant Constituents.Planta Medica 45: 3134.

Morshed, H. Islam, Md.S. Parvin, S. Uddin, M.A. Mostofa, A.G.M dan Sayyed, S.B.2012. Antimicrobial and Cytotoxuc Activity of the Methanol Extract of Peaderia foetida Linn. Journal of Applied Pharmaceitical Science. 02 (01); 2012: 77-80.

Rukmana. 2002. Mengkudu Budaya Dan Prospek Agribisnis. Yokyakarta: Kanisius.

Wijayakusuma, H. 2002. Atasi Asam Urat dan Rematik Ala Hembing. Jakarta:Niaga Swadaya. 